\title{
On our origins
}

\author{
David L. G. Noakes
}

Received: 13 January 2010 / Accepted: 22 February 2011 / Published online: 10 March 2011

(C) Springer Science+Business Media B.V. 2011

We marked 2009 devoted to origins. It was our way of acknowledging the coincidence of 2009 as the bicentennial of the birth of Charles Darwin, the sesquicentennial of his publication of The Origin of Species (Darwin 1859) - and the 170th anniversary of his marriage. A remarkable number and variety of books and articles devoted to Darwin were published to recognize the year (e.g., Quammen 2008; Dawkins 2009; Ruse 2009; van Wyhe 2009). Springer Academic Publishers recognized it as The Year of Darwin (Fig. 1). It is fitting to add our acknowledgement, given the importance of evolution to Environmental Biology of Fishes.

I invited Ian Potter to provide his article on the origin of Environmental Biology of Fishes (Potter 2010). Ian is in the unique position to provide that important information, as the only other remaining active member from the original Editorial Board of this journal (I was responsible for Notes and Reviews). Furthermore, he and Bill Beamish were the origin of the name of our journal! In this Editorial I will comment more specifically on the origin of Environmental Biology of Fishes and the development to the current state of our journal.

D. L. G. Noakes $(\bowtie)$

Fisheries \& Wildlife Department, Oregon State University, Room 120 Nash Hall,

Corvallis, OR 97331-3803, USA

e-mail: David.Noakes@oregonstate.edu
Origins, evolution and development are important to our journal, as they are to all of modern biology. Perhaps more than some other journals, Environmental Biology of Fishes emphasizes an evolutionary perspective. Our evolutionary emphasis shows not only in the articles we publish but also in the interests and activities of our Editorial Board. Of course we rely heavily on our external reviewers for their expertise and advice, and our panel of external reviewers is critical for reviews of our manuscripts. I will consider the Editorial Board and our published articles as the basis for my comments on the origin and development of Environmental Biology of Fishes. I have taken the information from the public forum, in the tables of contents, the lists of Advisory Editors, the Acknowledgements for Reviewing published in every volume, and of course most importantly the articles we publish. In addition, I have drawn upon the complete editorial files we maintain to provide critical details on the current status of the journal.

As Ian Potter described in his article (Potter 2010), our journal originated about 35 years ago, during a time of rapid growth for science and academia, at least in North America and Western Europe. Many changes have taken place over the ensuing quarter century, including recent economic upheavals, dramatic changes in technology and marked shifts in our perspectives on the natural world. Certainly the economic, social and other aspects of the historical context are important, but they are not the subjects of 


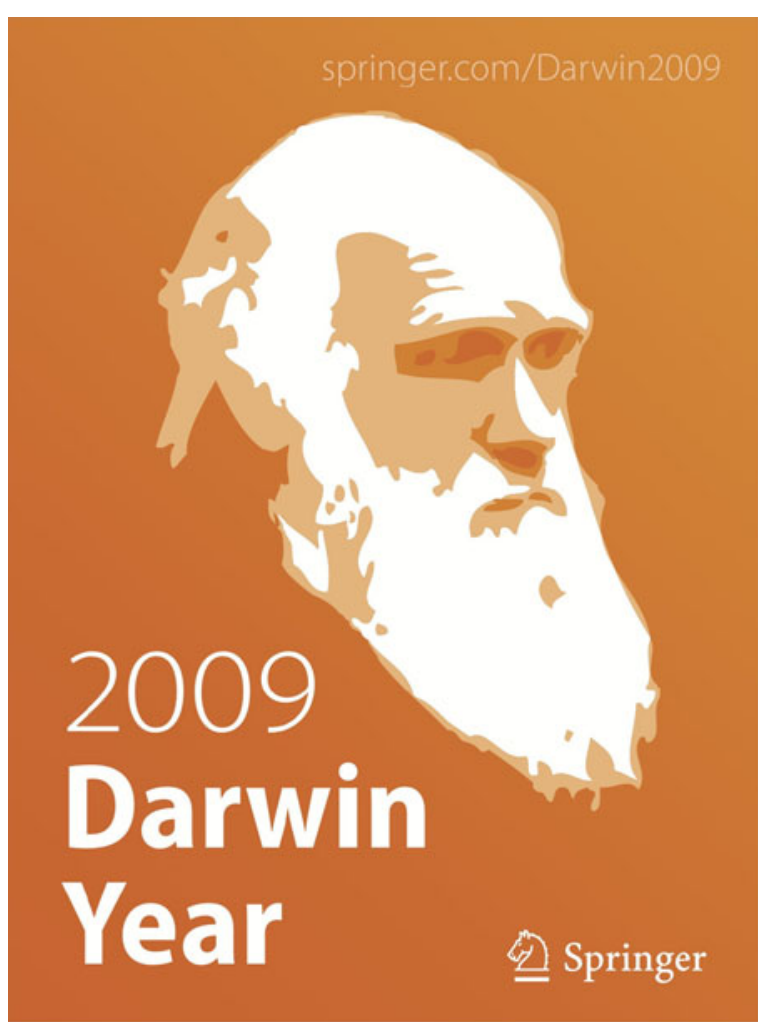

Fig. 1 The year of Darwin poster, Springer Academic Publishers

my consideration in this editorial. I am concerned with our science in our research articles and the affiliations of the authors and reviewers of those articles as indicators of the nature of our journal. We have stated from Volume 1, Issue 1 that Environmental Biology of Fishes is an international journal that publishes original studies on ecology, life history, epigenetics, behavior, physiology, morphology, systematics and evolution. I will review how we have accomplished that over our first quarter century.

For my comparison I chose two issues of Environmental Biology of Fishes: Volume 1, Number 1 (30 August 1976), the first issue, and Volume 85, Number 1 (May 2009) from a recent complete volume of the journal. Volume 1, Number 1 had 14 articles (111 pages) and was the only issue in that year (Volume 1, Number 2 was published 15 March 1977). Volume 85 , Number 1 had 15 articles (88 pages) so it appears that there might not be much difference in the overall "package" of the individual issues. Of course we now publish 12 issues each year so there is an enormous quantitative difference in the annual output of the journal. That comparison alone documents the very considerable growth of an order of magnitude in our journal in both the total content and the production rate of our journal. So our growth has been very considerable, but what about the content?

What have we demonstrated in our science, and how has that developed over time? I will focus my comparison on these two individual issues of the journal to judge the content and coverage, recognizing that the first issue represents the production for an entire year and the recent issue is the production for a single month. A number of important differences emerge from this comparison, and they tell us a great deal about the development of our journal.

I begin with a consideration of the Editorial Board. The original Editorial Board consisted of 12 individuals, including the Editor-in-Chief and 11 Advisory Editors (The list of Advisory Editors on the front cover of the first issue does not agree with the list on page 2, but the number of Advisory Editors was stated as 11 in the Preface). Those individuals were affiliated with academic or other scientific institutions in six countries: Australia, Canada, the USA, England, Israel and Germany. All but one of the original Editorial Board were males, the single exception (and an exceptional individual she remains) was Eugenie Clark. The Editorial Board in 2009 consisted of 21 members, including the Editor-in-Chief and 20 Advisory Editors, 17 male and four female. The 2009 Advisory Editors were affiliated with academic or other scientific institutions in eight countries: the USA, Canada, France, Argentina, Mexico, Japan, Australia and China. The number of members, the composition, and the international representation of the Editorial Board have all changed significantly since the founding of the journal in what must be interpreted as progressive ways.

Volume 1, Number 1 consisted of a Preface, an Invited Editorial, two Main research articles, three Notes, three Essays, three Book Reviews and Translation Proposals by authors from Canada, Poland and the USA. The two Main articles dealt with a study estimating the fish production of a freshwater lake in Canada, and the physiology of skipjack tuna (Katsuwonus pelamis). The three shorter notes dealt with teleost embryology, fish production, and technical aspects of rearing fish larvae.

Volume 85, Number 1 included an Editorial, and 14 articles that dealt with threatened fishes of the 
world, telemetry and behavior, field studies of spawning behavior, seasonal reproductive physiology, retinal structure and function, behavior, salinity tolerance, exotic and invasive species, impacts of habitat change on fish condition, and conservation of deep-sea fishes. Authors of the articles were from Canada, the USA, China, Uganda, Spain, Croatia, Costa Rica, Japan, Venezuela, New Zealand, Bolivia, and Germany.

The articles published in Volume 1, Number 1 were reviewed by 11 reviewers, 10 from Canada and 1 from Australia. For my comparison to the recent status of our journal I have chosen the period from 1 May to 31 August 2009 as representative and comparable to Volume 1, Number 1 (although again this comparison is 1 year for the first issue and only 4 months for the recent issue). During that period in 2009 we received 126 manuscripts from authors with affiliations in 13 countries (we had multiple authors from China for several manuscripts in the special issue on Chinese fishes), and we solicited reviews from external reviewers in 31 countries (Table 1). I repeat my earlier gratitude to this multitude of external reviewers who contribute so much to the journal. As we saw with the published articles and the Editorial Board, the coverage of our journal has clearly continued to grow not only in volume but also in scientific breadth and international coverage. As I have noted in previous Editorials, a number of independent metrics, including impact factor, also demonstrate this significant growth in the coverage and content of our journal.

Environmental Biology of Fishes continues its growth and development as a truly international journal. The special issue dedicated to Chinese Fishes (Volume 86, Number 1) is a recent example of our increasing coverage and impact. I have given details of the continued increases in the number and breadth of manuscripts handled, and the impact factor for the journal in previous Editorials (Noakes 2003, 2008). Development of the journal will continue, with special issues forthcoming on otoliths, threatened fishes and fish conservation, elasmobranch feeding behavior, and salmon biology, in addition to the latest research in contributed manuscripts. I will continue this series of Editorials to document those developments.

I conclude this Editorial with some more personal comments on growth, development and the year 2009. I presented the invited keynote address at the International Charr Symposium in Sterling, Scotland
Table 1 Summary of authors and reviewers of manuscripts received during the period of 1 May until 31 August 2009, according to their current affiliation addresses (in addition to the Advisory Editors who also review manuscripts, and whose affiliations are provided in the text)

\begin{tabular}{ll}
\hline Author affiliation & Reviewer affiliation \\
\hline Argentina & Brazil \\
Australia & Canada \\
Austria & China (multiple) \\
Brazil & Croatia \\
Canada & Germany \\
China (multiple) & Hong Kong \\
Czech Republic & Japan \\
Finland & Mexico \\
France & South Africa \\
Germany & Spain \\
Greece & Thailand \\
Iceland & USA \\
India & Venezuela \\
Italy & \\
Japan & \\
Mexico & \\
Mongolia & \\
Nepal & \\
Portugal & \\
Scotland & \\
South Africa & \\
Spain & \\
Sweden & \\
Taiwan & \\
Turkey & \\
United Kingdom & \\
\hline
\end{tabular}

in June 2009, where the focus was on Darwin ("Charles and Charr: 200 Years On"). During that address I emphasized the continuity and the connections we all have through our science to Darwin, his ideas and his influence. It is a relatively simple exercise to trace our individual scientific genealogies through our undergraduate and graduate advisors, as well as our intellectual contacts. For some of us our scientific heritage will lead, more or less directly, to Darwin. I hasten to add the obvious point, that 
Fig. 2 The Fitzwilliam Museum in Cambridge, England with the special Darwin exhibition for 2009 (photograph David L. G. Noakes)

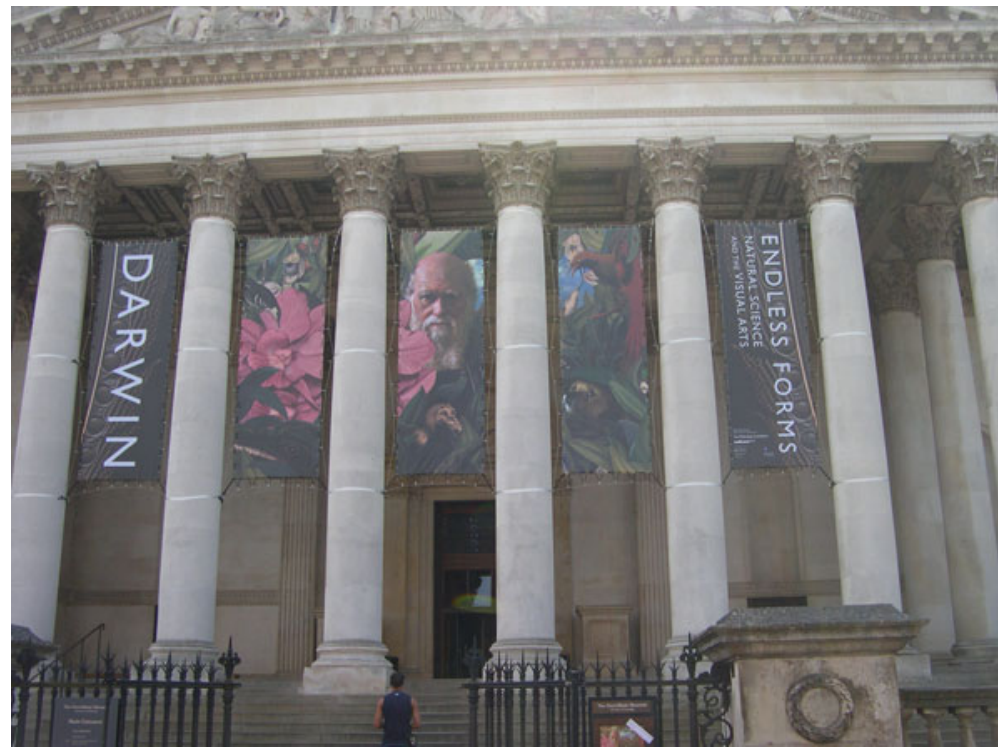

Darwin did not personally supervise any undergraduate or graduate students so our connections cannot literally lead directly to him. Nonetheless, ideas are as important to our scientific heritage as are the people, perhaps more so in many cases. Those ideas will leave trails as clear as the signatures of our supervisors on academic transcripts. Fortunately, we have historians and philosophers who seek out and document these connections and academic tracks and trails in science for us (Ruse 2009).

After my presentation at Stirling University, I revisited Edinburgh University - the site of my first academic position and coincidentally the location of Darwin's first attempt at a university education. Darwin withdrew from the unsatisfactory experience of his intended medical education at Edinburgh, but his biological education clearly benefited from his contacts there with Professor Robert Grant, his studies of lumpfish, Cyclopterus lumpus, and other marine creatures, and perhaps most significantly from his training in the preparation of study specimens by John Edmonston, a former slave who had experience in tropical expeditions (Berra 2009). From Edinburgh I traveled on to Cambridge, where Darwin had completed his formal university education, and where I toured a number of the special Darwin exhibitions staged for the year (Fig. 2). Finally, a visit to Oxford where I had spent a sabbatical year myself, and where the famous confrontation took place between Samuel
Wilberforce and Thomas H. Huxley, the great defender of Darwin after publication of The Origin of Species. A personal scientific pilgrimage, for sure, although I had visited all those places, and many of the other Darwin sites, Shrewsbury, Down House, Westminster Abbey and the Natural History Museum many times before. That is a pilgrimage every biologist should take.

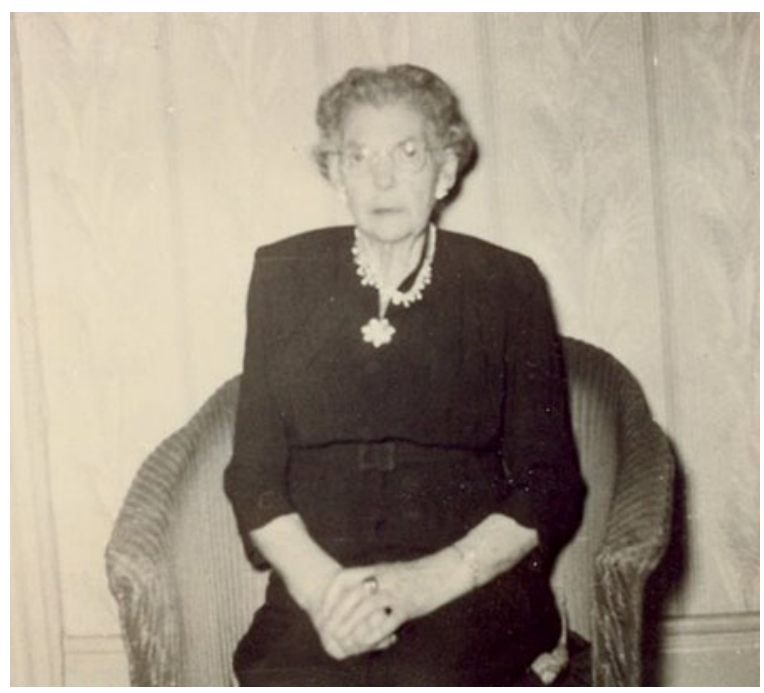

Fig. 3 Annie Proctor Richardson, at 92 years of age, seated in a chair now in my possession (photograph courtesy of Jean Noakes Park) 
My final point is poignant and most personal (Fig. 3). The lady in the photo is Annie Proctor Richardson, my paternal great-grandmother. She was born in 1865, the year Abraham Lincoln died. Abraham Lincoln was born 12 April 1809, the same day and the same year as Charles Darwin, as every biologist should know. Annie was 17 years old when Charles Darwin died (1882). I was 17 years old the year Annie died (1959). Of course I had known her well- she was the matriarch of the family, a tiny little lady dressed in black most of the time. How sad, I now realize, that I never talked to her about anything of substance. Of course there is absolutely no reason to believe that she had any experience or any opinion related to Charles Darwin. They certainly had nothing in common in terms of social or economic status. Charles and Emma Darwin had as many as 10 servants and staff in Down House. Annie Richardson worked "in service" as a young girl in England, that is she was a servant in the house of one of the wealthy families where she lived near Kendal, England. She lived the difficult life of a working class family with little formal education and few opportunities for any social or economic advancement. No doubt that grinding poverty and those dreary prospects influenced her decision to immigrate to Canada with her family early in the 20th century. Her family included the daughter (also named Annie) who would become my grandmother and who lived to visit me as a graduate student at the University of California at Berkeley and later read my postcards from Edinburgh and Oxford. This pilgrimage was thus also intensely personal.
Acknowledgements Suzanne Mekking, Lynn Bouvier and Martine van Bezooijen provided advice, encouragement, data summaries and constructive comments for this manuscript. Bill Beamish, Hiroya Kawanabe and Michael Ruse provided the critical comments and insightful suggestions I needed from trusted colleagues. Jeff Noakes commented on the historical aspects of the manuscript and Pat Noakes corrected my recollections. Jean Noakes Park provided the photo of Annie Proctor Richardson and reviewed the manuscript for consistency. I thank Springer Academic Publishers for their continued support for Environmental Biology of Fishes, and particularly for their recognition of The Year of Darwin. The Oregon Department of Fish and Wildlife and the Fisheries and Wildlife Department of Oregon State University provide my current academic home and continuing support.

\section{References}

Berra TM (2009) Charles Darwin. The concise story of an extraordinary man. The Johns Hopkins University Press, New York, p 114

Darwin CR (1859) On the origin of species by natural selection. John Murray, London, p 502

Dawkins R (2009) The greatest show on earth. The evidence for evolution. Free Press, New York, 470 pp

Noakes DLG (2003) Changes and continuity. Environ Biol Fish $66: 1-2$

Noakes DLG (2008) Growth and development. Environ Biol Fish 85:1-2

Potter IC (2010) On the origin: environmental biology of fishes. Environ Biol Fish 87:275-276

Quammen D (2008) Charles Darwin on the origin of species. The illustrated edition. Sterling, New York, p 544

Ruse M (2009) Philosophy after Darwin: classic and contemporary readings. Princeton University Press, Princeton, $\mathrm{p}$ 592

van Wyhe J (2009) Darwin in Cambridge. Christ's College, Cambridge, p 75 